\title{
A stochastic sampling approach to zircon eruption age interpretation
}

\section{C.B. Keller ${ }^{1,2^{*}}$, B. Schoene ${ }^{3}$, K.M. Samperton ${ }^{4}$}

Abstract

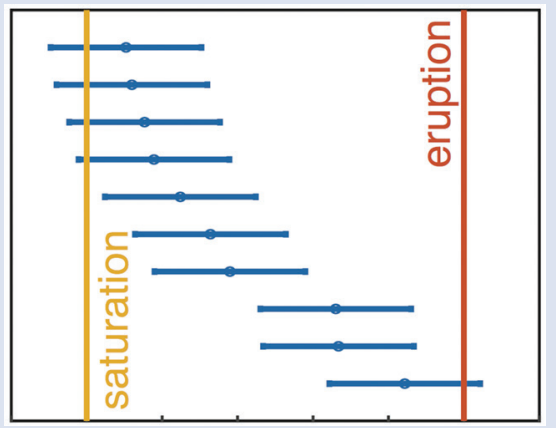

The accessory mineral zircon is widely used to constrain the timing of igneous processes such as magma crystallisation or eruption. However, zircon U-Pb ages record zircon crystallisation, which is not an instantaneous process. Zircon saturation calculations link zircon crystallisation, temperature, and melt fraction, allowing for the estimation of zircon crystallisation distributions as a function of time or temperature. Such distributions provide valuable prior information, enabling Bayesian estimates of magma eruption time and allowing for comparison of the relative accuracy of common weighted-mean and youngest-zircon age interpretations with synthetic datasets. We find that both traditional interpretations carry a risk of underestimating the uncertainty in eruption age; a low mean square of weighted deviates (MSWD) does not guarantee the accuracy of weighted-mean interpretations. In the absence of independent confirmation that crystallisation timescale is short relative to analytical uncertainties, a Bayesian approach frequently provides the most accurate results and is least likely to underestimate uncertainty. Since U-Pb zircon studies now routinely resolve geological age dispersion due to increasing analytical precision, such considerations are increasingly critical to future progress in resolving rates and dates of Earth processes.

Received 5 February 2018 | Accepted 13 September 2018 | Published 2 October 2018

\section{Introduction}

Absolute time constraints are critical for establishing temporal correlations, testing casual relationships, and quantifying rates and durations throughout the Earth sciences (Reiners et al., 2018). However, the time of radioisotopic closure may not directly date the geological events or processes of interest. Throughout the first century of geochronology, this potential mismatch was frequently a minor concern compared to analytical uncertainties at the percent level or greater. Recently, however, continual improvements in analytical precision and accuracy have fundamentally altered longstanding assumptions of geochronological age interpretation (Schoene, 2014).

One chronometer of particular interest is the U-Pb system in zircon, thanks to zircon's ubiquity, resilience, and tendency to exclude initial daughter isotopes. Throughout the geologic record, zircon provides crucial time constraints for processes ranging from evolution and mass extinction to magmatism and crustal differentiation (Bowring et al., 1993; Mundil et al., 2004; Harrison, 2009; Schoene et al., 2015; Samperton et al., 2017). Due to extremely slow parent and daughter isotope diffusion (Cherniak, 2003), zircon U-Pb ages record zircon crystallisation, if not compromised by metamictisation and subsequent $\mathrm{Pb}$ loss. However, the crystallisation of a suite of zircons in a single igneous rock sample has often been assumed to occur rapidly relative to analytical uncertainty, justifying the use of statistical approaches such as the weighted mean (e.g., Bowring et al., 1993). Moreover, even though zircon saturation in magmas is empirically well understood and distinct from whole rock crystallisation to the solidus (Boehnke et al., 2013), $\mathrm{U}-\mathrm{Pb}$ zircon ages are traditionally interpreted within uncertainty as reflecting bulk crystallisation or eruption.

While such assumptions may be justified for sufficiently ancient or homogeneous samples, crystallisation timescales may span 200-700 kyr for magmatic zircons (Lissenberg et al., 2009; Wotzlaw et al., 2013; Samperton et al., 2017). Consequently, diachronous crystallisation or recrystallisation must be considered before calculating a weighted mean of zircon ages derived from either in situ (SIMS, LA-ICPMS) or bulk (TIMS) analytical techniques. For instance, modern U-Pb Chemical Abrasion - Isotope Dilution TIMS (CA-ID-TIMS) ages (Mattinson, 2005) on single zircons and zircon fragments may surpass $0.05 \%(2 \sigma)$ accuracy and precision (e.g., Schoene et al., 2015; Samperton et al., 2017) - equivalent to 50 kyr in a 100 Ma sample. Consequently, zircon crystallisation

\footnotetext{
Berkeley Geochronology Center, Berkeley, CA 94709, USA

2. Department of Earth and Planetary Science, University of California, Berkeley, CA 94720, USA

3. Department of Geosciences, Guyot Hall, Princeton University, Princeton, NJ 08544, USA

4. Nuclear and Chemical Sciences Division, Lawrence Livermore National Laboratory, Livermore, CA 94550, USA

Corresponding author (email: cbk29@cornell.edu)
} 
age heterogeneity is increasingly clearly resolved in a wide range of magmatic contexts (Wotzlaw et al., 2013; Samperton et al., 2017).

Analogous issues appear in other geochronological applications ranging from the interpretation of anomalously dispersed Ar-Ar ages (e.g., Ellis et al., 2017) to the estimation of sedimentary depositional ages from detrital mineral geochronology. We consider here the case study of eruption age estimation by CA-ID-TIMS zircon geochronology, where analytical precision is high and confounding open system behaviour is relatively well controlled. Here, a plethora of competing age interpretations have developed in the literature, falling into three broad categories (e.g., Samperton et al., 2015) shown in Fig. 1f.

(1) Weighted mean. In cases where the variance of the dataset is plausibly consistent with analytical uncertainty alone, then some authors may calculate a weighted mean of the entire dataset (e.g., Crowley et al., 2007).

(2) Youngest zircon. In contrast, where there is an expectation of slow crystallisation relative to analytical uncertainty, or ages are highly dispersed, the youngest single analysis may be considered a better estimate of eruption age (e.g., Wotzlaw et al., 2013).

(3) Low MSWD weighted mean. As an intermediate between (1) and (2), one may calculate a weighted mean of only the $\mathrm{N}$ youngest analyses such that, given the acceptance distribution of the MSWD (Wendt and Carl, 1991), the MSWD of this subpopulation does not exceed a value deemed acceptable for $\mathrm{N}$ analyses (e.g., Schoene et al., 2015).

The possibility for residual lead loss, even following chemical abrasion, substantially complicates each of these three approaches, as does the common practice of excluding outliers subjectively identified as antecrysts. While interpretation (1) is likely to systematically pre-date the true eruption age, the accuracy of (2) and (3) has not been well tested. Moreover, while each interpretation has advantages, it is not clear that any of the three yields a statistically robust estimate of eruption age.

\section{Model Configuration}

In order to address these problems, we investigate the performance of common weighted-mean, youngest-zircon, and MSWD-test age interpretations, as well as that of an alternative likelihood-based Bayesian approach. To this end, we consider two dimensionless variables which, together with the pre-eruptive zircon crystallisation distribution $f\left(t_{r}\right)$, determine the behaviour of all possible volcanic zircon age interpretations. The first is $\Delta t / \sigma$, the ratio of the true crystallisation timescale $\Delta t$ to analytical uncertainty $\sigma$, while the second is simply $N$, the number of analyses (Fig. 1).

For instantaneous crystallisation $(\Delta t / \sigma=0)$ with Gaussian analytical uncertainty, both the mean and variance of an analytical dataset are constant as a function of $N$, and a weighted-mean interpretation is fully justified. However, these assumptions fail for non-trivial $\Delta t$, leading to systematic bias and potentially major over-estimation of accuracy and precision at high $N$. In contrast, at high $\Delta t / \sigma$, a youngest-zircon estimate is likely to outperform a weighted-mean interpretation, but may systematically pre- or post-date the true eruption age as a function of $N$.

The effectiveness of each approach will depend on $f\left(t_{r}\right)$. Fortunately, magmatic zircon crystallisation behaviour is understood via empirical saturation equations (Boehnke et al., 2013), kinetic models (Watson, 1996), and observation of natural systems (e.g., Samperton et al., 2017). In particular, we consider the mass of zircon crystallised per unit time or temperature per unit mass of magma. This intensive distribution should not be confused with the zircon populations considered by Caricchi et al. $(2014,2016)$, who assume constant zircon crystallisation rate per unit magma in the saturation interval (i.e. a flat line in Fig. 1a) in their attempt to estimate pluton-scale magma fluxes, which we do not consider here.
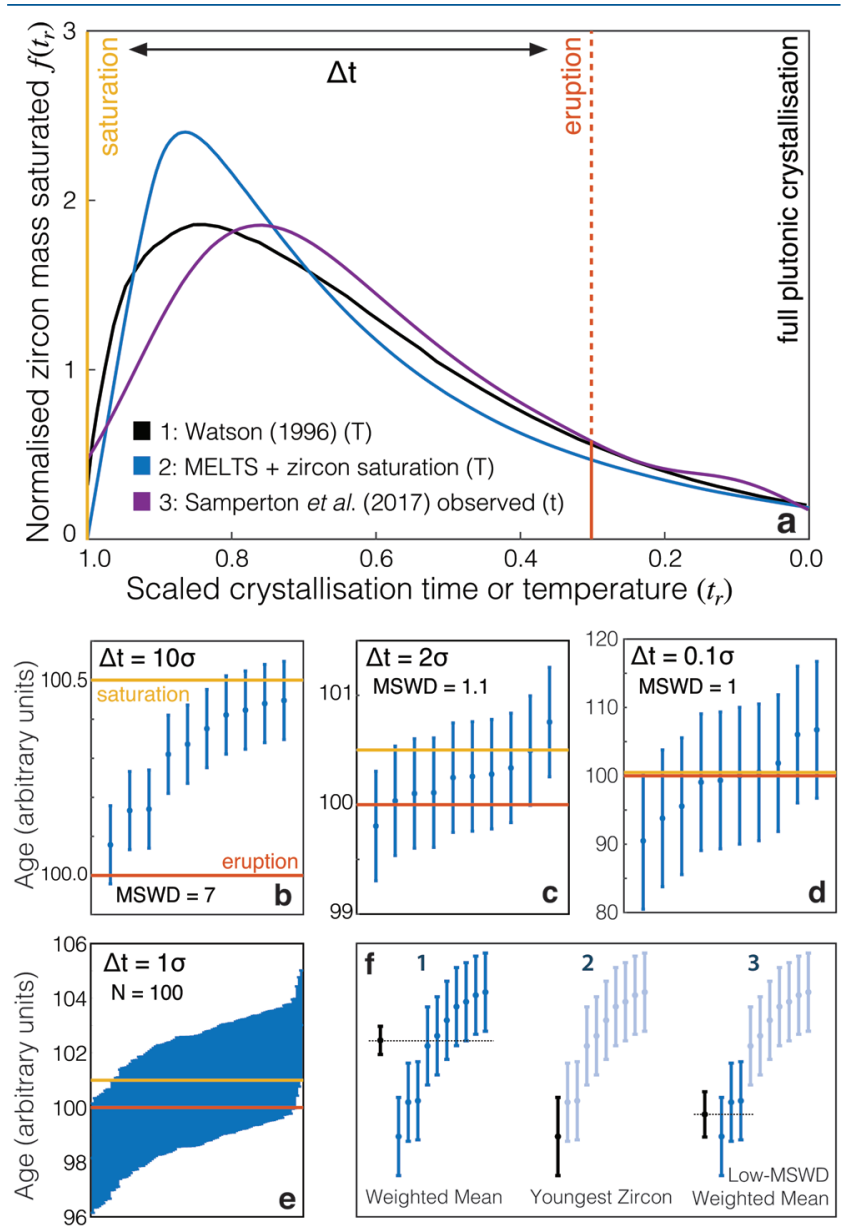

Figure 1 Zircon distributions. (a) Theoretical and empirical relative zircon crystallisation distributions $f\left(t_{r}\right)$, scaled from initiation to termination of zircon crystallisation. 1: Kinetic model of Watson (1996), based on zirconium diffusion constraints. 2: Thermodynamic model of Keller et al. (2017) using MELTS calculations. 3: Observed zircon crystallisation distributions of Samperton et al. (2017), shown as a kernel density estimate for all autocrystic zircons, truncated at $+/-1$ kernel bandwidth. (b-d) Representative synthetic zircon age datasets for a variety of $\Delta t / \sigma$ at $N=10$. (e) Example dataset with $N=100$ at $\Delta t=1 \sigma$; note the range is greater than in c despite lower $\Delta$ t. (f) Schematic illustration of the three most common volcanic zircon age interpretations.

Watson (1996) was the first to consider the form of the relative zircon crystallisation distribution as a function of temperature, calculating a theoretical distribution on the basis of kinetic constraints, characterised by a rapid onset of zircon crystallisation followed by a gradual decline. We also consider a thermodynamic model integrating major and trace element evolution with empirical zircon saturation equations (Boehnke et al., 2013; Keller et al., 2017), as well as an observed average plutonic zircon distribution (as a function of time) derived from CA-ID-TIMS of both single zircons and sub-grain zircon fragments (Samperton et al., 2017). All three approaches yield similar distributions, (Fig. 1a) - a consistency that extends in thermodynamic models to a wide range of whole rock 
compositions despite greatly varying saturation conditions (Fig. S-1). Distributions \#1 and \#2 assume linear cooling of a single magma batch; interaction of multiple magma batches and variable cooling rates may distort the distribution, though an abrupt truncation at eruption must feature in all volcanic zircon age spectra.

Given such a prior expectation of the form of $f\left(t_{r}\right)$, we may quantitatively test the performance of each common age interpretation as a function of $\mathrm{N}$ and $\Delta t / \sigma$ by drawing $\mathrm{N}$ zircons from a crystallisation distribution with arbitrary saturation and eruption ages, adding analytical uncertainty as a Gaussian random variable with variance $\sigma^{2}$ relative to the $\Delta t$ of the distribution, applying each age interpretation to the resulting synthetic dataset, and repeating the process very many times for each $N$ and $\Delta t / \sigma$ of interest. However, due to the consistency of theoretical and empirical zircon crystallisation distributions, we may also use such a distribution as prior information to constrain a likelihood-based Bayesian eruption age estimator as follows. Given an observed dataset and an accurate $f\left(t_{r}\right)$, one may readily calculate the likelihood of obtaining the observed dataset from the crystallisation distribution for any given saturation time and eruption time.

While a maximum-likelihood solution might be found by systematically varying both the saturation and eruption age to produce a two dimensional likelihood surface (e.g., Fig. S-2), such an exhaustive search would be inefficient. Instead, we follow the Metropolis algorithm to estimate the distribution of the eruption age, exploring the likelihood space by moving from its current position to a proposed position in the likelihood space with probability equal to the ratio of proposed and current likelihoods (maximum 1), with each proposal deviating from the previous position in only one dimension at a time (Gelman et al., 2013). After an initial period of equilibration, the series of accepted proposals takes the form of the stationary distribution of a Markov chain (Fig. S-3), which provides both the mean and variance of estimated zircon saturation and eruption ages. In order to test the sensitivity of this approach to the choice of $f\left(t_{r}\right)$, we calculate Bayesian eruption age estimates using (1) the MELTS crystallisation distribution (Fig. 1a) from which the synthetic data were drawn, (2) a uniform relative crystallisation distribution (i.e. a flat line in Fig. 1a), and (3) a "bootstrapped" distribution, a truncated kernel density estimate of each synthetic dataset (Methods).

\section{Results}

We explore the parameter space from $\Delta t / \sigma$ of 0.01 to 10 and $N$ of 1 to 1000, which includes ranges applicable to both ID-TIMS and in situ geochronological techniques. As expected, weighted means are accurate at very low $\Delta t / \sigma$, with the lowest absolute error and accurate reported uncertainty at $\Delta t=0.01 \sigma$ (Fig. $2 \mathrm{a}, \mathrm{e})$, but fail at high $\Delta \mathrm{t} / \mathrm{\sigma}$, with absolute error not lower than $\Delta t / 2$ and highly inaccurate reported uncertainty (Fig. 2d,h). Conversely, the youngest-zircon approach performs poorly at $\Delta t=0.01 \sigma$ with high absolute error and substantial over-precision, but comparatively well at $\Delta t=10 \sigma$. Such interpretations might remain useful if $\Delta t / \sigma$ were readily determinable for natural datasets.

Problems emerge at intermediate levels of age dispersion. At $\Delta t=1 \sigma$, all three traditional interpretations begin to fail visibly above $\mathrm{N}=3$, with high absolute error in youngest-zircon interpretations, and under-estimated uncertainty in both weighted-mean and low-MSWD weighted-mean interpretations, for instance by a factor of two at $\mathrm{N}=10$ (Fig. $2 b, f)$. At $\Delta t=2 \sigma$, the problems with weighted-mean interpretations are accentuated, while youngest-zircon interpretations coincidentally perform well at moderate $\mathrm{N}$ (due to competing biases which happen to cancel at $N=5$ and $\Delta t=2 \sigma$ ), but ultimately still fail at high $\mathrm{N}$ due to analytical outliers.

These problems are compounded by the fact that the average MSWD at $\Delta t=2 \sigma$ is only 1.26 , statistically indistinguishable from the near-unity MSWD of a dataset with $\Delta t=$ $0.01 \sigma$ until one has characterised more than 700 individual zircon analyses (Fig. S-4). Even magmatic age heterogeneity as high as $\Delta t=5 \sigma$ is not clearly distinguishable from instantaneous crystallisation on the basis of MSWD for datasets smaller than $N \approx 50$, and data sets with $\Delta t / \sigma$ less than two are generally indistinguishable from instantaneous crystallisation at any practical N (Fig. S-4).
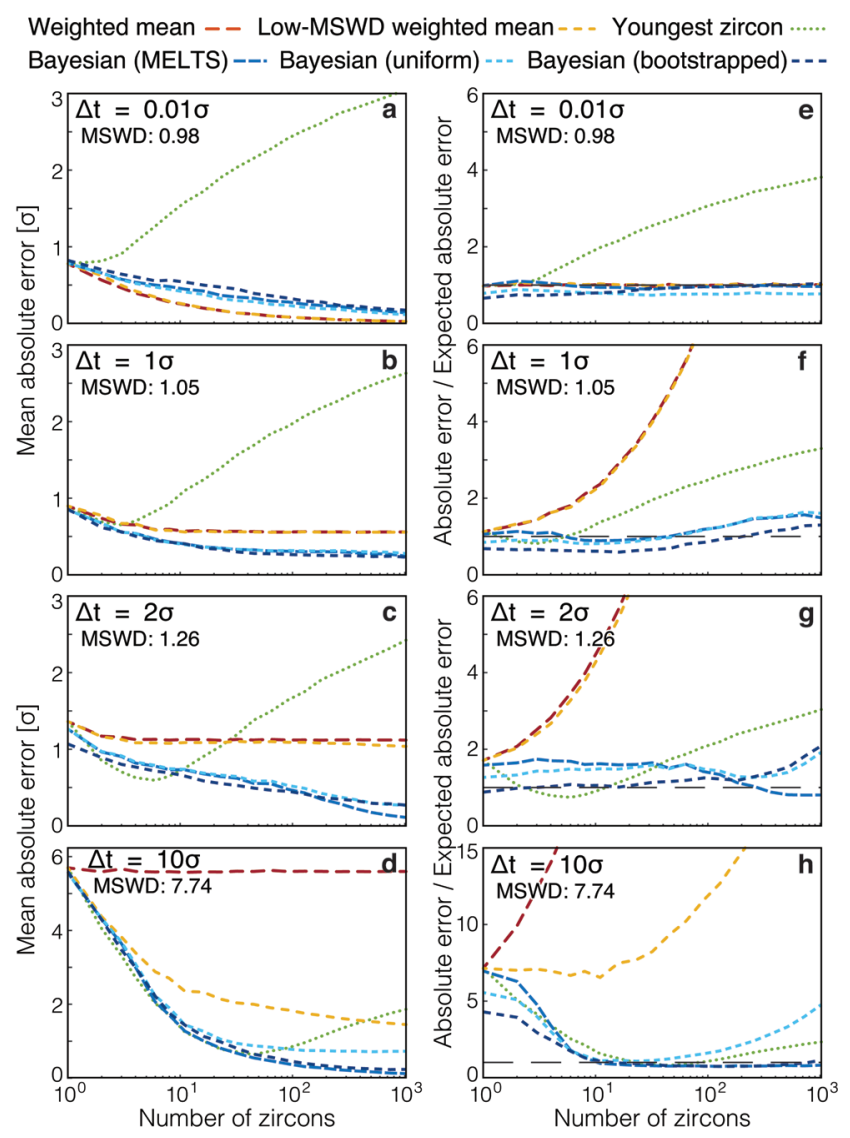

Figure 2 Performance of each age interpretation as a function of $\mathrm{N}$ and $\Delta \mathrm{t} / \mathrm{\sigma}$. (a-d) Mean absolute error is the mean absolute deviation of the model result from the true value; lower absolute errors are better. (e-h) Accuracy of the model uncertainty for each age interpretation. A value greater than 1.0 indicates an under-estimation of the model uncertainty (i.e. over-precision), while a value lower than 1.0 indicates an over-estimation of the model uncertainty. MSWD in each panel is the average mean square of weighted deviation (also known as the reduced chi squared statistic) for that $\Delta t / \sigma$ over all $N$. Each datum reflects the mean of 1200 synthetic dataset tests; standard error of the mean is on the order of the line width.

In contrast, the Bayesian eruption age estimate yields slightly higher absolute error than the weighted mean at $\Delta t=0.01 \sigma$, but otherwise equals or outperforms all other approaches across a wide range of $\mathrm{N}$ and $\Delta \mathrm{t} / \mathrm{\sigma}$, with the closest to consistently accurate reported uncertainties. Notably, this result is not highly sensitive to the exact choice of $f\left(t_{r}\right)$, as the Bayesian estimate assuming a uniform $f\left(t_{r}\right)$ only diverges from the equivalent estimate assuming the true prior at high $\Delta t / \sigma$, and only then for $N$ greater than typical in TIMS studies (ca. 5-20). 

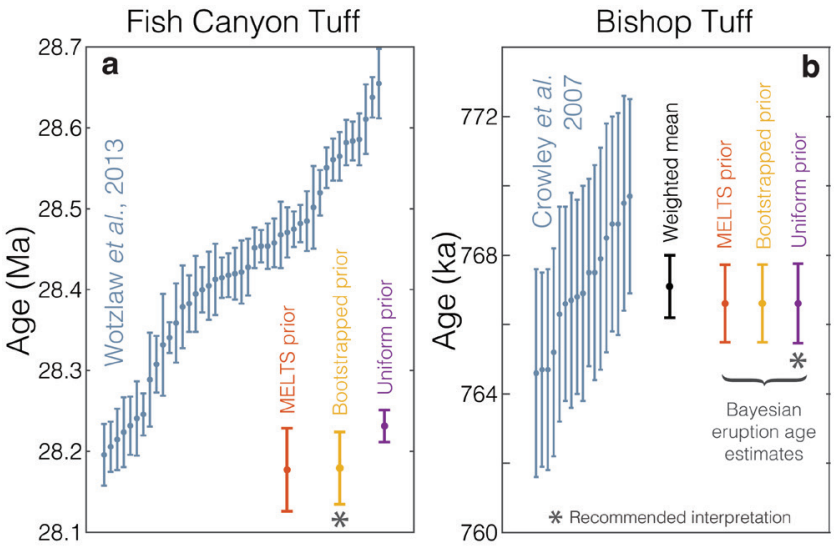

Figure 3 Bayesian eruption age estimates for two well known volcanic zircon populations. For age spectra with well-resolved dispersion (a), a kernel density estimate may recover a close approximation of $f\left(t_{r}\right)$, obviating the need to identify and reject antecrysts. However, for age spectra where igneous dispersion is not well resolved (b), assuming a uniform $f\left(t_{r}\right)$ may be more parsimonious.

To explore the practical application of Bayesian eruption age estimation, we consider ID-TIMS datasets from two wellknown super-eruptions with contrasting zircon age spectra: the 28 Ma Fish Canyon Tuff, with $~ 500$ kyr of continuous zircon age dispersion (Wotzlaw et al., 2013), and the more homogeneous 767 kyr Bishop Tuff (Crowley et al., 2007). As seen in Figure 3, the results are suggestive of a youngest-zircon interpretation for the Fish Canyon Tuff and a weighted-mean interpretation for the Bishop Tuff - congruous with the dramatic difference in dispersion between the two datasets. If all zircons were strictly autocrystic, the presence of older outliers would suggest that we are incompletely sampling the zircon saturation distribution, and thus over-estimating the eruption age. Including xenocrystic outliers in the Bayesian age interpretation thus counter-intuitively leads to under-estimation of the eruption age and divergence between Bayesian and weighted-mean ages for the Bishop Tuff (e.g., Fig. S-5).

\section{Discussion}

Considering the results of Figure 2 in context of the variance of the MSWD (Fig. S-4), for most natural datasets we cannot rely on sufficiently low $\Delta t / \sigma$ to justify a weighted-mean interpretation even at low MSWD, nor in general can we justify a youngest-zircon interpretation except at low $\mathrm{N}$ and high MSWD. In the absence of reliable external evidence for instantaneous crystallisation, the greater precision obtained by a weighted-mean approach is illusory. A likelihood-based Bayesian estimate appears to perform competitively under all scenarios, and is the least likely to underestimate the reported uncertainty.

The problem of minimum age estimation may also be considered from the perspective of mixture modelling, which can be approached either numerically or analytically (Galbraith, 2005; Jasra et al., 2006), and is also likely to outperform the "traditional" interpretations. In this context, the main advantage of our approach compared to an analytical equivalent is merely the ability to specify numerically an arbitrary $f\left(t_{r}\right)$ derived from a physics-based model.

While our approach may decrease the impact of subjective interpretational decisions, it does not eliminate them entirely: we must still choose a method by which to estimate $f\left(t_{r}\right)$. This relative crystallisation distribution is well-determined for a single magma batch (Fig. 1a \#1-2), and may be empirically estimated ("bootstrapped") by a kernel density estimate in datasets with highly- resolved dispersion (Fig. 1a \#3). Even when data are inverted with an $f\left(t_{r}\right)$ that does not match the distribution from which they were drawn, a Bayesian approach still significantly outperforms traditional interpretations (Fig. 2, Figs. S-6, S-7). Nonetheless, distortions may occur, particularly in datasets featuring extreme outliers, or if our critical assumption that $f\left(t_{r}\right)$ falls to zero at $t_{r}=0$ (i.e. no crystallisation after eruption) is violated by contamination, unrecognised lead loss, or other open system behaviour.

Finally, while the similarity in form between the observed and theoretical relative crystallisation distributions $f\left(t_{r}\right)$ (Fig. 1a) suggests that single zircon and zircon fragment TIMS ages are sampling (and not simply integrating) the true $f\left(t_{r}\right)$, further systematic analysis is required. The ideal U-Pb zircon technique to resolve such geochronological problems must provide high analytical accuracy, high spatial resolution, and the ability to mitigate lead loss. Consequently, we recommend sub-grain microsampling or microfracturing wherever possible in TIMS analyses (e.g., Samperton et al., 2017), and emphasise further study of the effects and detection of lead loss for all $\mathrm{U}-\mathrm{Pb}$ techniques.

\section{Acknowledgements}

Thanks to B. Dyer and J.-F. Wotzlaw for discussion and to P. Vermeesch, K. Gallagher, U. Schaltegger, and T. Sheldrake for valuable reviews. CBK. was supported in part by the Department of Energy Computational Science Graduate Fellowship Program of the Office of Science and National Nuclear Security Administration under contract DE- FG02-97ER25308. Computational support was provided by the Princeton Institute for Computational Science and Engineering. Lawrence Livermore National Laboratory is operated by Lawrence Livermore National Security, LLC, for the U.S. Department of Energy, National Nuclear Security Administration under Contract DE-AC52-07NA27344. All source code is available at https://github.com/brenhinkeller/BayeZirChron.c

\section{Editor: Graham Pearson}

\section{Additional Information}

Supplementary Information accompanies this letter at http:// www.geochemicalperspectivesletters.org/article1826.

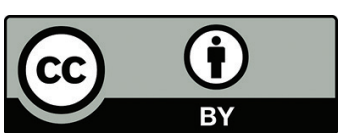

This work is distributed under the Creative Commons Attribution 4.0 License, which permits unrestricted use, distribution, and reproduction in any medium, provided the original author and source are credited. Additional information is available at htt p://www.geochemicalperspectivesletters.org/ copyright-and-permissions.

Cite this letter as: Keller, C.B., Schoene, B., Samperton, K.M. (2018) A stochastic sampling approach to zircon eruption age interpretation. Geochem. Persp. Let. 8, 31-35.

\section{References}

Boehnke, P., Watson, E.B., Trail, D., Harrison, T.M., Schmitt, A.K. (2013) Zircon saturation re-revisited. Chemical Geology 351, 324-334.

Bowring, S.A., Grotzinger, J.P., Isachsen, C., Knoll, A., Pelechaty, S., Kolosov, P. (1993) Calibrating rates of early Cambrian evolution. Science 261, 1293-1298. 
CARICCHI, L., Simpson, G., Schaltegger, U. (2014) Zircons reveal magma fluxes in the Earth's crust. Nature 511, 457-461.

Caricchi, L., Simpson, G., Schaltegger, U. (2016) Estimates of volume and magma input in crustal magmatic systems from zircon geochronology: the effect of modelling assumptions and system variables. Frontiers in Earth Science 4, 1-15.

CHERnIAK, D.J. (2003) Diffusion in Zircon. Reviews in Mineralogy and Geochemistry 53, 113-143.

Crowley, J.L., Schoene, B., Bowring, S.A. (2007) U-Pb dating of zircon in the Bishop Tuff at the millennial scale. Geology 35, 1123-1126.

Ellis, B.S., Mark, D.F., Troch, J., Bachmann, O., Guillong, M., Kent, A.J.R., VON QUADT, A. (2017) Split-grain 40Ar/39Ar dating: Integrating temporal and geochemical data from crystal cargoes. Chemical Geology 457, 15-23.

GalbRAith, R. (2005) Statistics for Fission Track Analysis. CRC Press.

Gelman, A., Carlin, J.B., Stern, H.S., Dunson, D.B., Vehtari, A., Rubin, D.B. (2013) Bayesian Data Analysis. CRC Press.

HARrison, T.M. (2009) The Hadean Crust: Evidence from 4 Ga Zircons. Annual Review of Earth and Planetary Sciences 37, 479-505.

Jasra, A., Stephens, D.A., Gallagher, K., Holmes, C.C. (2006) Bayesian Mixture Modelling in Geochronology via Markov Chain Monte Carlo. Mathematical Geology 38, 269-300.

Keller, C.B., Boehnke, P., Schoene, B. (2017) Temporal variation in relative zircon abundance throughout Earth history. Geochemical Perspectives Letters 3, 179-189.

Lissenberg, C.J., Rioux, M., Shimizu, N., Bowring, S.A., Mével, C. (2009) Zircon Dating of Oceanic Crustal Accretion. Science 323, 1048-1050.

MAtTinson, J.M. (2005) Zircon U-Pb chemical abrasion ("CA-TIMS") method: Combined annealing and multi-step partial dissolution analysis for improved precision and accuracy of zircon ages. Chemical Geology 220, 47-66.

Mundil, R., Ludwig, K.R., Metcalfe, I., Renne, P.R. (2004) Age and Timing of the Permian Mass Extinctions: U/Pb Dating of ClosedSystem Zircons. Science 305, 1760-1763.

Reiners, P.W., Carlson, R.W., Renne, P.R., Cooper, K.M., Granger, D.E., MCLean, N.M., Schoene, B. (2018) Geochronology and Thermochronology. John Wiley \& Sons.

Samperton, K.M., Schoene, B., Cottle, J.M., Keller, C.B., Crowley, J.L., SCHMITZ, M.D. (2015) Magma emplacement, differentiation and cooling in the middle crust: Integrated zircon geochronologicalgeochemical constraints from the Bergell Intrusion, Central Alps. Chemical Geology 417, 322-340.

Samperton, K.M., Bell, E.A., Barboni, M., Keller, C.B., Schoene, B. (2017) Zircon age-temperature-compositional spectra in plutonic rocks. Geology 45, 983-986.

Schoene, B. (2014) 4.10 U-Th-Pb Geochronology. In: Rudnick, R.L. (Ed.) Treatise on Geochemistry, Second Edition. Elsevier, 341-378.

Schoene, B., Samperton, K.M., Eddy, M.P., Keller, G., Adatte, T., Bowring, S.A., KHADRI, S.F.R., GERTSCH, B. (2015) U-Pb geochronology of the Deccan Traps and relation to the end-Cretaceous mass extinction. Science 347, 182-184.

WATSON, E.B. (1996) Dissolution, growth and survival of zircons during crustal fusion: kinetic principles, geological models and implications for isotopic inheritance. Transactions of the Royal Society of Edinburgh: Earth Sciences 87, 43-56.

WENDT, I., CARL, C. (1991) The statistical distribution of the mean squared weighted deviation. Chemical Geology 86, 275-285.

Wotzlaw, J.F., Schaltegger, U., Frick, D.A., Dungan, M.A., Gerdes, A., GÜNTHER, D. (2013) Tracking the evolution of large-volume silicic magma reservoirs from assembly to supereruption. Geology 41, 867-870. 